\title{
Thermotropic Liquid Crystalline Polyesters using Aromatic Rigid Diols, Unsaturated Fumaric Acid and Flexible Sebacic Acid
}

\author{
Apparav Wale, Smita Mule, Atul Dhage, Khudbudin Mulani, Surendra Ponrathnam, Nayaku \\ Chavan*
}

Chemical Engineering and Process Development Division, National Chemical Laboratory, Dr. Homi Bhabha Road, Pashan Pune-411 008, India

\section{A R T I C L E I N F O}

Received: 14 November 2019

Revised: 20 December 2019

Accepted: 05 January 2020

Available online: 07 January 2020

\section{K E Y W O R D S}

Unsaturated polyesters

Flexible

Rigid

Liquid crystalline

Thermotropic

\section{A B S T R A C T}

In the present study, seven different series of thermotropic liquid crystalline polyesters (TLCPs) containing unsaturated fumaroyl chloride and flexible sebacoyl chloride were synthesized using the interfacial polymerization methodology. Homopolyesters prepared with saturated flexible spacer such as sebacoyl chloride were mesomorphic whereas homopolyesters synthesized using unsaturated aliphatic spacer such as fumaroyl chloride that was non-mesomorphic. Aromatic diad and triad based mesogenic diols were selected as rigid moiety for liquid crystalline phase formation. Within each series, copolyesters were synthesized by varying relative mole ratio of the above two aliphatic diacid chlorides. Most of the liquid crystalline polyesters showed solubility in phenol:tetrachloroethane $(60: 40)$ at $40{ }^{\circ} \mathrm{C}$.

\section{G R A P H I C A L A B S TRACT}

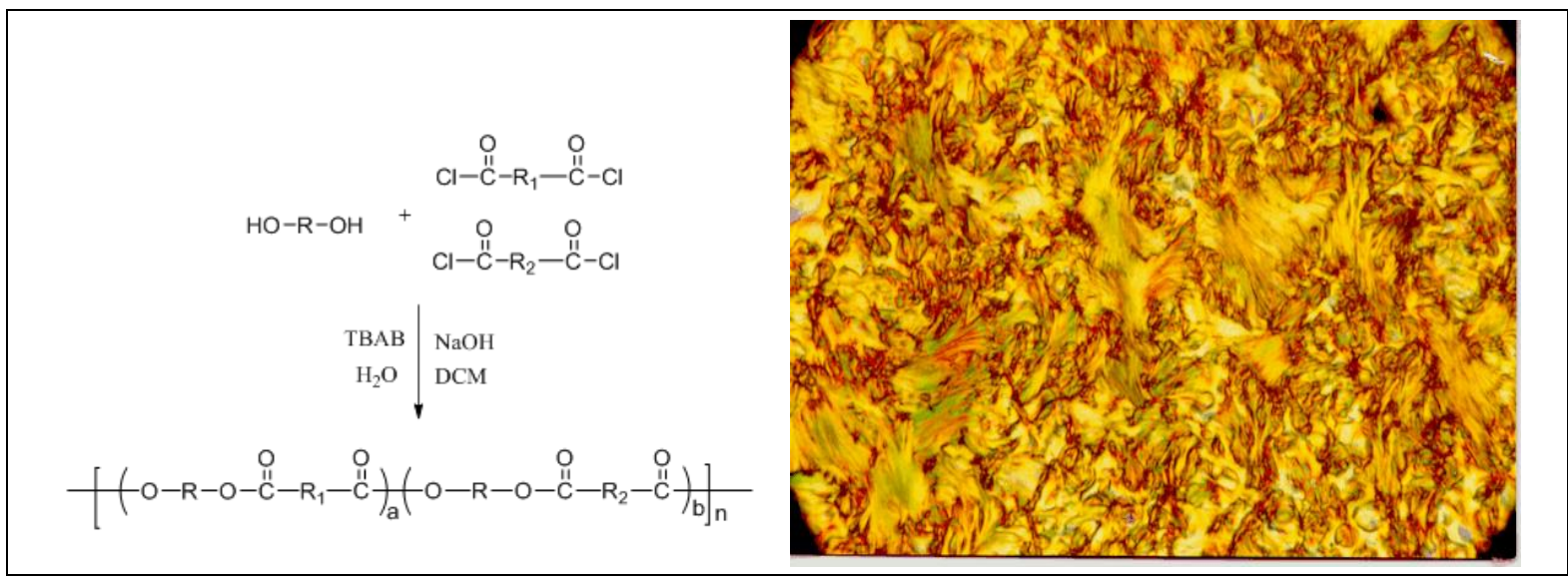

* Corresponding author's E-mail address: nn.chavan@ncl.res.in 


\section{Introduction}

Liquid crystalline polymers (LCPs) are increasingly used worldwide in industrial and commercial applications as special materials in diverse fields such as delivery devices, ophthalmic devices and ink compositions for toner for photocopying, tissue engineering and other areas including biomedical applications [1-3]. However, properties related to orientation decreases considerably due to anisotropy. To overcome this problem introduction of reactive double bond into the polymer main chain was worked out. The literature on unsaturated polyesters describes extensive use of maleates whereas fumarates are rarely reported. The typical functional crosslinkable units in the main chain are cinnamoyl, $p$-phenylene, diacryl or stilbene. Functional end groups frequently used are maleimide, epoxy, vinyl, isocyanate, acetylene or acrylate [4]. The liquid crystalline polymers derived from fumarates and mesogenic methoxyphenyl azophenoxy resulting in formation of the enantiotropic nematic phase. Properties of liquid crystalline thermosets based on types of reactants and methods of synthesis were already described by many researchers [5-11].

The unsaturated polymers can be crosslinked thermally or photochemically. The network structure is based on rigid rod or extended chain segments that are crosslinked in three dimensions. The introduction of fumaroyl units into flexible spacer of liquid crystal polymers allows a structure fixing crosslinking reaction. Thus, unsaturated polyesters with liquid crystal elements can be synthesized by incorporating combination of rigid mesogenic unit with rigid fumarate units along the chain.

Liquid crystalline thermosets are a class of materials that combine properties typical of thermotropic liquid crystalline polymers with those of conventional thermosets. Mulani et al. [12] observed very large mesophasic stability for new liquid crystalline polyesters consisting of bis-(4hydroxybenzoyloxy)-2- methyl-1,4-benzene and aliphatic dicarboxylic acid chlorides [12]. Applications of liquid crystal thermosets include the advanced adhesives, new matrix materials for composites and variety of applications for microelectronics industry. These compounds have also been studied as optical materials and polarizers [13].

Thermotropic liquid crystalline polymers are exhibiting a class of high-performance polymers, because these polymers exhibit very good thermal and mechanical properties. Due to the attractive properties these polymers are applied in variety of fields such as electronic devices, protective coatings, sports equipment, and automotive part composites [14].

Thermotropic liquid crystalline polymers are usually based on type of polyesters, because these polymers possess free hydrogen bond linkages. The polymers such as poly(4-oxybenzoyl), poly(4-phenylene terephthalate) and poly(4-phenylene naphthalene-2,6-dicarboxylate) melt at very high temperature. From the technological point of view, polyesterification of these polymers is carried out by melt polycondensation method and processing temperature is above $400{ }^{\circ} \mathrm{C}$. As high processing temperature number of side reactions takes place; it affects the quality of the final product. Another major drawback of fully aromatic TLCPs is insolubility in common organic solvents namely chloroform, dichloromethane, tetrahydrofuran, ethyl acetate, acetone, toluene, and aprotic solvents such as NMP, DMF, DMSO, and DMAc. This insolubility exhibited due to high axial ratio and highly crystalline nature of the polymers; as they are difficult to process [15].

To enhance the processability of these TLCPs, various approaches have been 
performed to reduce the crystal perfection and the crystal lattice energy include : i) insertion of flexible spacer into the main chain of polymer to reduce axial ratio of the mesogen; ii) introduction of substitution on aromatic ring of mesogenic moiety to disturb regularity of the repeating unit; iii) addition of cycloaliphatic monomer or kink into the main chain of polymer backbone; iv) incorporating crank-shaft monomers; and v) copolymerisation of different mesogens. Random arrangement of repeating units also lowers the transition temperature [16].

In the present work, series of main chain homo and copolyesters based on thermotropic liquid crystalline polymeric nature were synthesised by interfacial polycondensation method. Rigid mesogenic diols were condensed in combination with fumaroyl chloride and sebacoyl chloride. Fumaroyl chloride acts as rigid unsaturated aliphatic diacid whereas sebacoyl chloride performs as flexible aliphatic diacid.

\section{Experimental}

\section{Materials and methods}

Solvents such as dichloromethane, methanol, chloroform, dichloromethane, dichloroethane, tetrachloroethane, and tetrahydrofuran were procured from Merck and used as received. The chemicals such as phenol, sodium hydroxide and 4,4'-biphenol (BP) were purchased from Merck and were used as received. The diacid chlorides were obtained from Aldrich chemical company and were used as such. Aromatic diols e.g. 4,4'-dihydroxyazobenzene (AZ), 4,4'dihydroxyazoxybenzene (AX), 4,4'dihydroxy-3,3'-dimethylazoxybenzene (AXM), 2,6-bis(4-hydroxy benzylidene) cyclohexanone (BC), 2,6-bis(4-hydroxy benzylidene)-4-methyl cyclohexanone (BM), bis (4-hydroxy benzoyloxy) 2-chloro1,4-benzene (BHOC) were synthesized by established procedures [17].
Synthesis of polyesters by interfacial polymerization

Stock solutions of diacid chlorides were prepared by accurately weighing 0.001 mole of each acid chloride in $100 \mathrm{~mL}$ volumetric flask and making volume up to the mark with dry distilled 1,2-dichloroethane. To $50 \mathrm{~mL}$ erlenmeyer flask, $0.002 \mathrm{~mol}$ of diol was accurately weighed, dissolved in $20 \mathrm{~mL}$ of 0.2 $\mathrm{N}$ sodium hydroxide solution and transferred into reactor using $20 \mathrm{~mL}$ of distilled water. Tetrabutyl ammonium bromide (TBAB), a phase transfer catalyst (4 wt.\% of diol) was then added, followed by $40 \mathrm{~mL}$ of 1,2dichloroethane. Then required amount of the diacid chlorides was added and the reactants were vigorously stirred for $5 \mathrm{~min}$. Subsequently $500 \mathrm{~mL}$ methanol was added to precipitate the polymer. Polymer obtained was filtered and dried under the reduced pressure at $40{ }^{\circ} \mathrm{C}$ for $8 \mathrm{~h}$. Schematic representation of interfacial polymerization is shown in Scheme 1. Synthesized homo and copolyesters were characterized by infrared spectroscopy (IR), differential scanning calorimetry (DSC), and polarizing optical microscopy.

\section{Solubility of polyesters}

Solubility of the polyesters was tested in organic solvents such as chloroform, carbon tetrachloride, 1,2-dichloroethane, dichloromethane, 1,1,2,2-tetrachloroethane, tetrahydrofuran, acetone, methanol and phenol:1,1,2,2-tetrachloroethane (60:40, $\mathrm{v} / \mathrm{v}$ ). Into $10 \mathrm{~mL}$ volumetric flask, $20 \mathrm{mg}$ of polymer and $10 \mathrm{~mL}$ of desired solvent were added and kept aside for 3 days at ambient temperature with intermittent stirring. To avoid possibility of crosslinking through olefinic double bond of fumaroyl moiety, the solutions were not heated [18]. The intrinsic viscosity $(\eta)$ of selected polymers was estimated using an Ubbelohde viscometer using $0.5 \mathrm{~g} / \mathrm{dL}$ solution prepared in 
phenol:tetrachloroethane $\quad(60: 40, \quad \mathrm{v} / \mathrm{v})$ mixture, kept for $24 \mathrm{~h}$ for complete dissolution, filtered and then viscosity was measured.
Scheme 1. Schematic representation for synthesis of polyesters

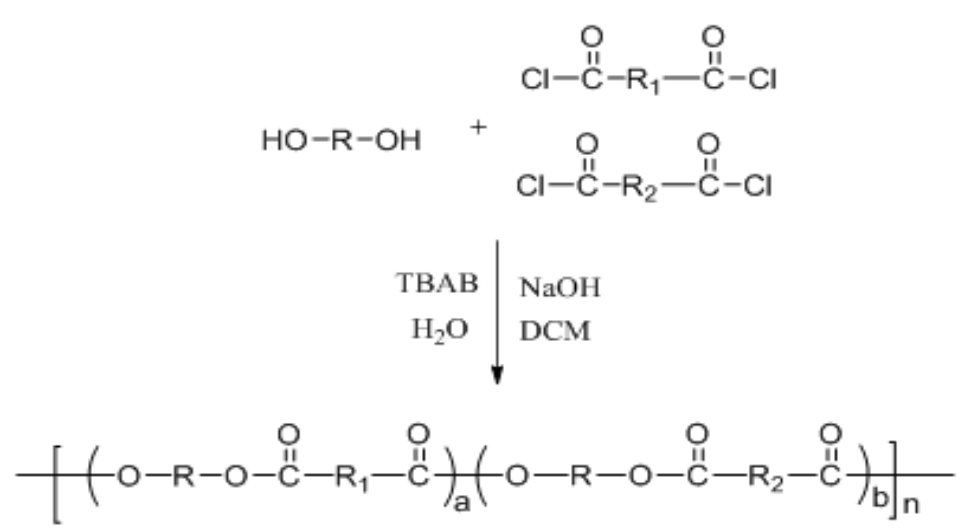

Where R:

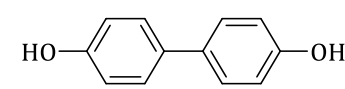

4,4'- Biphenol (BP)

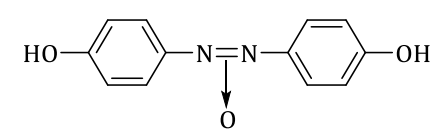

4,4'-Dihydroxyazoxybenzene (AX)

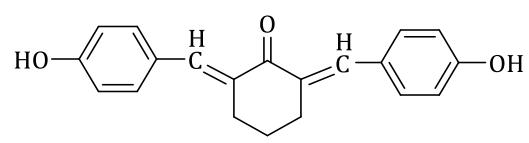

2,6-Bis(4-hydroxy benzylidene) cyclohexanone (BC)

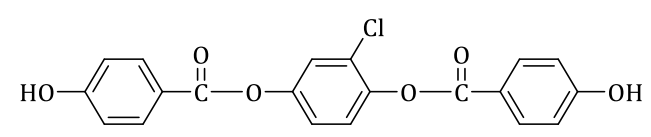

Bis (4-hydroxy benzoyl oxy) 2-chloro-1, 4-benzene (BHOC)

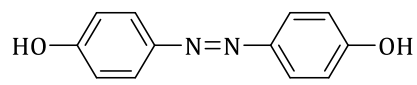

4,4'-Dihydroxyazobenzene (AZ)<smiles>Cc1cc(N=[14C]=Nc2ccc(O)c(C)c2)ccc1O</smiles>

4,4'-Dihydroxy-3,3'-dimethylazoxybenzene (AXM)<smiles>CC1CC(=Cc2ccc(O)cc2)C(=O)C(=Cc2ccc(O)cc2)C1</smiles>

2,6-Bis(4-hydroxy benzylidene)-4-methyl cyclohexanone (BM)

Where R1: Fumaroyl chloride and R2: Sebacoyl chloride

\section{Thermal analysis}

DSC analysis of the synthesized polyesters was conducted using Mettler-4000 thermal analyzer and DSC-30 cell. Temperature calibration was made by using Indium-LeadZinc standards. All samples were heated from room temperature to $300{ }^{\circ} \mathrm{C}$ at a rate of $10{ }^{\circ} \mathrm{C} / \mathrm{min}$ (first heating cycle) after that sample was heated for $5 \mathrm{~min}$ isothermally at same temperature then cooled back to room temperature at the cooling rate of $10{ }^{\circ} \mathrm{C} / \mathrm{min}$ (first cooling cycle). After that the same sample was reheated from room temperature to $450{ }^{\circ} \mathrm{C}$ at a rate $10{ }^{\circ} \mathrm{C} / \mathrm{min}$ to evaluate glass transition temperature and melting temperatures of polymers (second heating cycle). Thermal transitions were reported as the maxima and minima of their endothermic or exothermic peaks, respectively. For DSC analysis, 4-9 $\mathrm{mg}$ of 
sample was weighed. Empty pans were weighed to match within a deviation of \pm $0.002 \mathrm{mg}$.

\section{Optical polarizing microscopy}

Optical polarizing microscopic study was conducted under the crossed polarized light with Carl Zeiss microscope equipped with hot stage and Leitz 350 hot stage coupled to Leitz Laborlux 12 POLs microscope. Photographs were taken using Leica wild MP SSZ/46 photoautomat system. The polymer grains were held between cover slip and glass plate and heated gradually $\left(5-10{ }^{\circ} \mathrm{C}\right)$ to desire temperature (selected from thermal transitions observed in DSC thermogram). Morphology of thin layer of material, which formed above glass transition and melting temperature, was studied visually during heating as well as cooling with optical polarizing microscope.

\section{Results and discussion}

Rigid rod-flexible spacer based thermotropic liquid crystalline polyesters were synthesized by interfacial polymerization methodology and its monomer compositions are presented in Table 1. In these series, seven different types of aromatic rigid diols were used namely 4,4'-biphenol (BP), 4,4' dihydroxyazobenzene (AZ), 4,4'dihydroxyazoxybenzene (AX), 4,4'dihydroxy-3,3'-dimethylazoxybenzene (AXM), 2,6-bis(4-hydroxy benzylidene) cyclohexanone (BC), 2,6-bis(4-hydroxy benzylidene)-4-methyl cyclohexanone (BM), and bis (4-hydroxy benzoyloxy)-2chloro-1, 4-benzene (BHOC).

\section{Solubility of polyesters}

Solubility study of all synthesized thermotropic liquid crystalline polyesters was checked in organic solvents such as chloroform, carbon tetrachloride, 1,2dichloroethane, dichloromethane, tetrahydrofuran, acetone, methanol and phenol/1,1,2,2- tetrachloroethane mixture $(60: 40, v / v)$ and are presented in Table 2 . Into $10 \mathrm{~mL}$ volumetric flask, $20 \mathrm{mg}$ of polymer and $10 \mathrm{~mL}$ of desired solvent were added and kept aside for 3 days at ambient temperature with intermittent stirring. To avoid possibility of crosslinking through olefinic double bond of fumaroyl moiety, the solutions were not heated [18]. All these polyesters were insoluble in almost all chlorinated solvents such as chloroform, carbon tetrachloride, dichloromethane and 1,2-dichloroethane and also in acetone and tetrahydrofuran. But all these liquid crystalline polyesters showed solubility in phenol:tetrachloroethane $\quad(60: 40, \quad \mathrm{v} / \mathrm{v})$ solvent system at $40{ }^{\circ} \mathrm{C}$.

\section{Intrinsic viscosity}

Intrinsic viscosity of the thermotropic liquid crystalline polyesters was determined at a concentration of $0.5 \mathrm{~g} / \mathrm{dL}$ in phenol:tetrachloroethane $(60: 40, \mathrm{v} / \mathrm{v})$ using an Ubbelohde viscometer at $40{ }^{\circ} \mathrm{C}$ and are presented in Table 2. Polyesters coded as $5 \mathrm{BP}, 5 \mathrm{AX}$ and $4 \mathrm{AX}$ showed lower viscosity whereas polyester coded as $5 \mathrm{BC}$ and $5 \mathrm{BM}$ showed considerable good viscosities such as 0.56 and $0.49 \mathrm{dL} / \mathrm{g}$ respectively. It indicates that polyesters prepared from cyclohexanone based diols showed higher viscosity than biphenol and azoxy based diols.

\section{IR spectroscopy}

IR spectral measurements of powder polymer samples embedded in potassium bromide disc were carried out with Shimadzu IR-470 spectrophotometer. The discs were prepared using 1-2 mg of dried sample and $100 \mathrm{mg}$ of spectroscopic grade sieved (200 mesh) potassium bromide. 
Table 1. Monomer composition for synthesis of LCPs by interfacial polycondensation

\begin{tabular}{|c|c|c|c|c|c|c|c|}
\hline \multirow{3}{*}{$\begin{array}{l}\text { Sr. } \\
\text { No. }\end{array}$} & \multirow{3}{*}{$\begin{array}{l}\text { Polymer } \\
\text { Code }\end{array}$} & \multirow{2}{*}{\multicolumn{2}{|c|}{ Aromatic diols }} & \multicolumn{4}{|c|}{ Aliphatic diacid chloride } \\
\hline & & & & \multicolumn{2}{|c|}{ Fumaroyl chloride } & \multicolumn{2}{|c|}{ Sebacoyl chloride } \\
\hline & & Mole & g & Mole & g & Mole & g \\
\hline 1 & 1BP & \multirow{5}{*}{0.002} & \multirow{5}{*}{0.3724} & 0.002 & 0.3059 & 0 & 0 \\
\hline 2 & 2BP & & & 0.0015 & 0.2293 & 0.0005 & 0.1125 \\
\hline 3 & 3BP & & & 0.001 & 0.1529 & 0.001 & 0.2251 \\
\hline 4 & 4BP & & & 0.0005 & 0.0764 & 0.0015 & 0.3376 \\
\hline 5 & $5 B P$ & & & 0 & 0 & 0.002 & 0.4502 \\
\hline 6 & $1 \mathrm{AZ}$ & \multirow{5}{*}{0.002} & \multirow{5}{*}{0.4284} & 0.002 & 0.3059 & 0 & 0 \\
\hline 7 & $2 \mathrm{AZ}$ & & & 0.0015 & 0.2293 & 0.0005 & 0.1125 \\
\hline 8 & $3 \mathrm{AZ}$ & & & 0.001 & 0.1529 & 0.001 & 0.2251 \\
\hline 9 & $4 \mathrm{AZ}$ & & & 0.0005 & 0.0764 & 0.0015 & 0.3376 \\
\hline 10 & $5 \mathrm{AZ}$ & & & 0 & 0 & 0.002 & 0.4502 \\
\hline 11 & $1 \mathrm{AX}$ & \multirow{5}{*}{0.002} & \multirow{5}{*}{0.4604} & 0.002 & 0.3059 & 0 & 0 \\
\hline 12 & $2 \mathrm{AX}$ & & & 0.0015 & 0.2293 & 0.0005 & 0.1125 \\
\hline 13 & $3 A X$ & & & 0.001 & 0.1529 & 0.001 & 0.2251 \\
\hline 14 & $4 \mathrm{AX}$ & & & 0.0005 & 0.0764 & 0.0015 & 0.3376 \\
\hline 15 & $5 A X$ & & & 0 & 0 & 0.002 & 0.4502 \\
\hline 16 & $1 \mathrm{AXM}$ & \multirow{5}{*}{0.002} & \multirow{5}{*}{0.5165} & 0.002 & 0.3059 & 0 & 0 \\
\hline 17 & $2 \mathrm{AXM}$ & & & 0.0015 & 0.2293 & 0.0005 & 0.1125 \\
\hline 18 & 3АXM & & & 0.001 & 0.1529 & 0.001 & 0.2251 \\
\hline 19 & 4AXM & & & 0.0005 & 0.0764 & 0.0015 & 0.3376 \\
\hline 20 & $5 A X M$ & & & 0 & 0 & 0.002 & 0.4502 \\
\hline 21 & $1 \mathrm{BC}$ & \multirow{5}{*}{0.002} & \multirow{5}{*}{0.6122} & 0.002 & 0.3059 & 0 & 0 \\
\hline 22 & $2 B C$ & & & 0.0015 & 0.2293 & 0.0005 & 0.1125 \\
\hline 23 & $3 B C$ & & & 0.001 & 0.1529 & 0.001 & 0.2251 \\
\hline 24 & $4 \mathrm{BC}$ & & & 0.0005 & 0.0764 & 0.0015 & 0.3376 \\
\hline 25 & $5 B C$ & & & 0 & 0 & 0.002 & 0.4502 \\
\hline 26 & $1 \mathrm{BM}$ & \multirow{5}{*}{0.002} & \multirow{5}{*}{0.6407} & 0.002 & 0.3059 & 0 & 0 \\
\hline 27 & $2 \mathrm{BM}$ & & & 0.0015 & 0.2293 & 0.0005 & 0.1125 \\
\hline 28 & 3BM & & & 0.001 & 0.1529 & 0.001 & 0.2251 \\
\hline 29 & $4 \mathrm{BM}$ & & & 0.0005 & 0.0764 & 0.0015 & 0.3376 \\
\hline 30 & 5BM & & & 0 & 0 & 0.002 & 0.4502 \\
\hline 31 & $1 \mathrm{BHOC}$ & \multirow{5}{*}{0.002} & \multirow{5}{*}{0.7735} & 0.002 & 0.3059 & 0 & 0 \\
\hline 32 & 2BHOC & & & 0.0015 & 0.2293 & 0.0005 & 0.1125 \\
\hline 33 & 3 BHOC & & & 0.001 & 0.1529 & 0.001 & 0.2251 \\
\hline 34 & 4 BHOC & & & 0.0005 & 0.0764 & 0.0015 & 0.3376 \\
\hline 35 & $5 \mathrm{BHOC}$ & & & 0 & 0 & 0.002 & 0.4502 \\
\hline
\end{tabular}

Table 2. Solubility and viscosity data of polyesters

$\begin{array}{cllllllllc}\text { Polyester } & \mathrm{a} & \mathrm{b} & \mathrm{c} & \mathrm{d} & \mathrm{e} & \mathrm{f} & \mathrm{g} & \mathrm{h} & \text { Viscosity* (dL/g) } \\ 5 \mathrm{BP} & \mathrm{x} & \mathrm{x} & \mathrm{x} & \mathrm{x} & \mathrm{x} & \mathrm{x} & \mathrm{x} & \sqrt{ } & 0.20 \\ 5 \mathrm{AZ} & \mathrm{x} & \mathrm{x} & \mathrm{x} & \mathrm{x} & \mathrm{x} & \mathrm{x} & \mathrm{x} & \sqrt{ } & -- \\ 5 \mathrm{AX} & \mathrm{x} & \mathrm{x} & \mathrm{x} & \mathrm{x} & \mathrm{x} & \mathrm{x} & \mathrm{x} & \sqrt{ } & 0.07 \\ \text { 4AX } & \mathrm{x} & \mathrm{x} & \mathrm{x} & \mathrm{x} & \mathrm{x} & \mathrm{x} & \mathrm{x} & \sqrt{ } & 0.12 \\ 5 \mathrm{AXM} & \mathrm{x} & \mathrm{x} & \mathrm{x} & \mathrm{x} & \mathrm{x} & \mathrm{x} & \mathrm{x} & \sqrt{ } & -- \\ 5 \mathrm{BC} & \mathrm{x} & \mathrm{x} & \mathrm{x} & \mathrm{x} & \mathrm{x} & \mathrm{x} & \mathrm{x} & \sqrt{ } & 0.56 \\ 5 \mathrm{BM} & \mathrm{x} & \mathrm{x} & \mathrm{x} & \mathrm{x} & \mathrm{x} & \mathrm{x} & \mathrm{x} & \sqrt{ } & 0.49\end{array}$

Where, a: chloroform, b: carbon tetrachloride, c: 1,2-dichloroethane, d: dichloromethane, e: tetrahydrofuron, f: acetone, g: methanol, h: phenol:tetrachloroethane (60:40);

* intrinsic viscosity determined in phenol:tetrachloroethane $(60: 40, \mathrm{v} / \mathrm{v})$ at $40{ }^{\circ} \mathrm{C}$ 
IR spectra of rigid diol BP, homopolyester (1BP) based on 4,4'-dihydroxy biphenyl (BP) with $100 \%$ fumaroyl chloride (unsaturated rigid aliphatic spacer) and homopolyester (5BP) based on 4,4'-dihydroxy biphenyl (BP) with $100 \%$ sebacoyl chloride (saturated flexible spacer) are depicted in Figure 1.

IR spectrum of biphenol (BP) showed characteristic peaks at $3500-3600 \mathrm{~cm}^{-1}$ (primary O-H stretching), 2900-3000 $\mathrm{cm}^{-1}$ (C-H stretching), $1600 \mathrm{~cm}^{-1}$ (aromatic $\mathrm{C}=\mathrm{C}$ stretching), $1200 \mathrm{~cm}^{-1}$ (C-O-C stretching), and $800 \mathrm{~cm}^{-1}$ (1,4-disubstitution). IR spectrum of homopolyester (1BP) prepared from biphenol and $100 \%$ fumaroyl chloride exhibited characteristic peaks at $3400-3500 \mathrm{~cm}^{-1}(\mathrm{O}-\mathrm{H}$ stretching), 2900-3000 $\mathrm{cm}^{-1}$ (C-H stretching), $1730-1760 \mathrm{~cm}^{-1}$ (ester carbonyl), $1220 \mathrm{~cm}^{-1}$ (O$\mathrm{H}$ bending, phenolic), $1100-1150 \mathrm{~cm}^{-1}$ (C-O-C stretching), $900-1000 \mathrm{~cm}^{-1}$ (C=C bending) and $720 \mathrm{~cm}^{-1}$ (long chain). IR spectrum of homopolyester (5BP) prepared from biphenol and $100 \%$ sebacoyl chloride displayed characteristic peaks at $3400-3500 \mathrm{~cm}^{-1}(\mathrm{O}-\mathrm{H}$ stretching), 2900-3000 $\mathrm{cm}^{-1}$ (C-H stretching), $1730-1760 \mathrm{~cm}^{-1}$ (ester carbonyl), $1220 \mathrm{~cm}^{-1}$ (O$\mathrm{H}$ bending, phenolic), $1100-1150 \mathrm{~cm}^{-1}$ (C-O-C stretching) and $720 \mathrm{~cm}^{-1}$ (long chain).

Copolyesters prepared within series using rigid diols, unsaturated rigid aliphatic spacer and flexible aliphatic spacers differ only in composition relative to the mole fraction of rigid aliphatic spacer to flexible aliphatic spacer. It shows almost identical overall IR spectra but differs in the intensity of characteristic peaks. Major difference between the rigid and flexible spacer is unsaturated double bond present in fumaroyl chloride appeared at $900 \mathrm{~cm}^{-1}$ to 1000 $\mathrm{cm}^{-1}$. Spectroscopic data obtained was in good agreement with the proposed structure $[10,19]$.

\section{Thermal analysis}

Thermal analysis data measured by differential scanning calorimetry (DSC) and polarizing optical microcopy (POM) are presented in Table 3 and discussion about behaviors of individual series is as follows.

\section{DSC analysis of BP series}

Thermal properties of the thermotropic liquid crystalline polyesters were determined using the DSC analysis. The results are presented in Table 3. DSC thermograms of the liquid crystalline polyesters of $1 \mathrm{BP}$ and $5 \mathrm{BP}$ are depicted in Figure 2. The homopolyester 1BP, no change in baseline was observed till $250{ }^{\circ} \mathrm{C}$. It showed two transitions at $270{ }^{\circ} \mathrm{C}$ and $>300{ }^{\circ} \mathrm{C}$ which corresponds to glass transition temperature and decomposition respectively. No exotherm was observed in the first cooling cycle. It indicates that mesophasic phase was not formed, thus, it did not show any characteristics of liquid crystalline phase. DSC thermogram of 1BP is depicted in Figure 2a. Copolyester 2BP, exhibited two transition temperatures at $260{ }^{\circ} \mathrm{C}$ and $>300{ }^{\circ} \mathrm{C}$ which corresponds to glass transition temperature and decomposition respectively and was not showing any characteristics of liquid crystalline phase. Copolyester 3BP also displayed two transition temperatures particularly at $210{ }^{\circ} \mathrm{C}$ and $>300{ }^{\circ} \mathrm{C}$, which correspond to glass transition temperature and decomposition respectively. This copolyester also did not show any characteristics of mesophase formation. Copolyester 4BP also allowed two transition temperatures particularly at $170^{\circ} \mathrm{C}$ and $>300^{\circ} \mathrm{C}$ which corresponds to glass transition temperature and decomposition respectively. The copolyester 5BP revealed two transitions at $115{ }^{\circ} \mathrm{C}$ and $185{ }^{\circ} \mathrm{C}$ which correspond to glass transition temperature and melting temperature respectively. This copolyester showed liquid crystalline phase in the range of 220-260 ${ }^{\circ} \mathrm{C}$. The copolyester 5BP expressed two endothermic transitions in the first heating cycle and these were retained in the second heating. On cooling, two exotherms were observed at $166^{\circ} \mathrm{C}$ and $106^{\circ} \mathrm{C}$. DSC thermogram of $5 \mathrm{BP}$ is depicted in Figure $2 \mathrm{~b}$. Typical polarizing optical micrograph of $5 \mathrm{BP}$ at $246^{\circ} \mathrm{C}$ 
during heating depicted in Figure 3 and showed smectic batonnet texture.

Figure 1. Superimposed Infra-red spectra of 1BP, 5BP and diol BP where 1B: 1BP, 5B: 5BP and B: BP

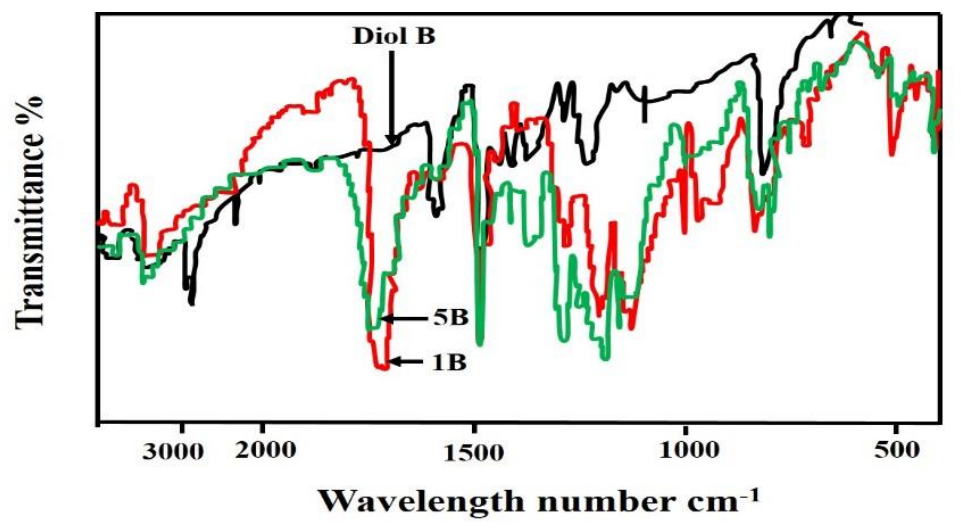

Table 3. Thermal properties of polyesters observed by DSC

\begin{tabular}{|c|c|c|c|}
\hline Polymer code & $\begin{array}{l}\mathrm{Tg} \\
\left({ }^{\circ} \mathrm{C}\right)\end{array}$ & $\begin{array}{l}\mathrm{Tm} \\
\left({ }^{\circ} \mathrm{C}\right)\end{array}$ & $\begin{array}{c}\text { LC phase } \\
\left({ }^{\circ} \mathrm{C}\right)\end{array}$ \\
\hline $1 \mathrm{BP}$ & 270 & $>300 \mathrm{~d}$ & -- \\
\hline 2BP & 260 & $>300$ & -- \\
\hline $3 \mathrm{BP}$ & 210 & $>300 \mathrm{~d}$ & -- \\
\hline $4 \mathrm{BP}$ & 170 & $>300 \mathrm{~d}$ & -- \\
\hline $5 \mathrm{BP}$ & 115 & 185 & $220-260$ \\
\hline $1 \mathrm{AZ}$ & -- & 145 & -- \\
\hline $2 \mathrm{AZ}$ & 161 & 208 & $210-236$ \\
\hline $3 \mathrm{AZ}$ & 129 & 142,158 & $209-250$ \\
\hline $4 \mathrm{AZ}$ & 145 & 177,201 & 194-265 \\
\hline $5 \mathrm{AZ}$ & -- & 178,207 & $190-246$ \\
\hline $1 \mathrm{AX}$ & -- & 143 & -- \\
\hline $2 \mathrm{AX}$ & -- & 140,164 & $219-250$ \\
\hline $3 A X$ & -- & 134,150 & $200-255$ \\
\hline $4 A X$ & 145 & 156 & $190-265$ \\
\hline $5 A X$ & -- & 143,168 & $190-260$ \\
\hline $1 \mathrm{AXM}$ & -- & -- & -- \\
\hline 2AXM & 129 & 143 & -- \\
\hline 3AXM & 133 & 143 & $145-175$ \\
\hline 4AXM & 155 & 180 & 154-186 \\
\hline $5 A X M$ & 118 & 143 & $130-150$ \\
\hline $1 \mathrm{BC}$ & -- & 200 & -- \\
\hline $2 \mathrm{BC}$ & -- & 150 & -- \\
\hline $3 \mathrm{BC}$ & 48 & 128,230 & -- \\
\hline $4 \mathrm{BC}$ & 115 & 181 & -- \\
\hline $5 \mathrm{BC}$ & 134 & 107,146 & $170-196$ \\
\hline $1 \mathrm{BM}$ & -- & 115 & -- \\
\hline 2BM & -- & 144 & -- \\
\hline 3BM & -- & 130 & -- \\
\hline $4 \mathrm{BM}$ & 134 & 146 & -- \\
\hline $5 \mathrm{BM}$ & -- & 124,182 & $170-185$ \\
\hline $1 \mathrm{BHOC}$ & -- & $145,163,174$ & -- \\
\hline 2BHOC & -- & 335 & -- \\
\hline 3 BHOC & -- & 144,250 & -- \\
\hline $4 \mathrm{BHOC}$ & -- & 132 & -- \\
\hline $5 \mathrm{BHOC}$ & -- & 206 & $216-285$ \\
\hline
\end{tabular}



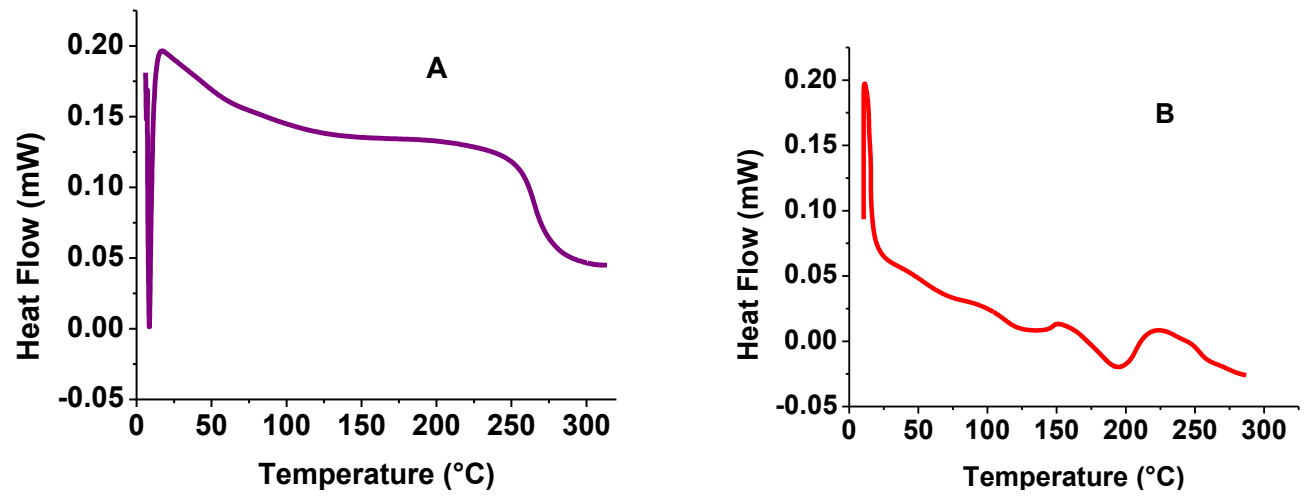

Figure 2. A) DSC thermogram of 1BP during first heating; B) DSC thermogram of 5BP during first heating

Figure 3. Optical polarizing micrograph of 5BP showing Smectic batonnet texture at $246{ }^{\circ} \mathrm{C}$ during heating (Magnification 20X)

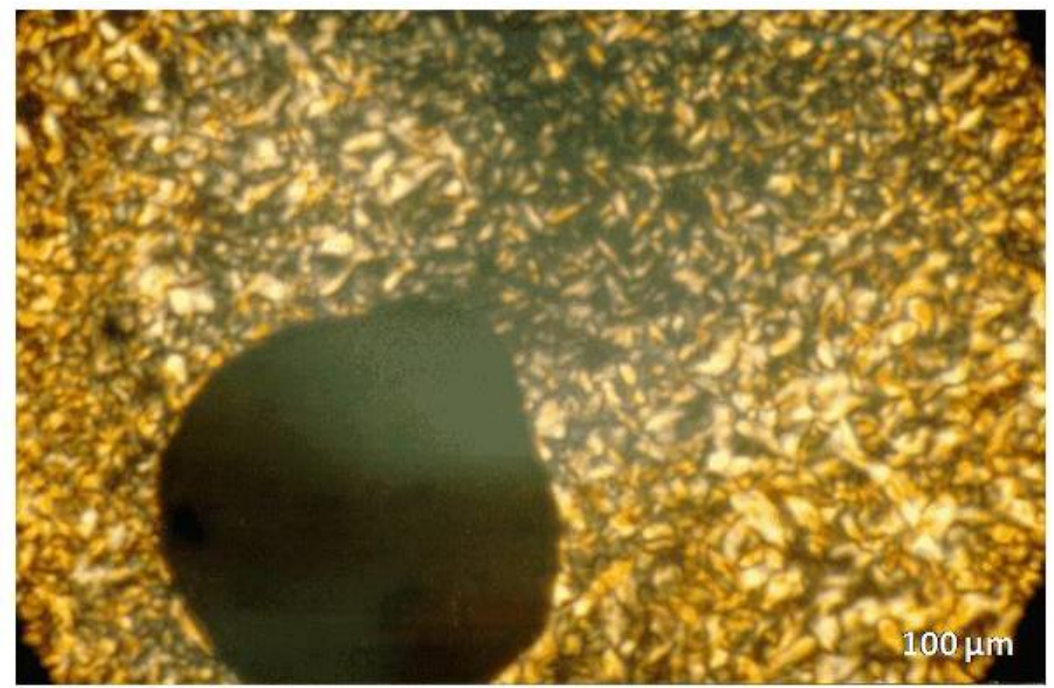

In general, DSC study of liquid crystalline polyesters based on BP diol with aliphatic diacid chlorides showed decrease in glass transition temperature with increase in sebacoyl chloride content. This trend is attributed to the content of fumaroyl chloride in polyester backbone. Basically fumaroyl chloride contains unsaturated double bond and this double bond forms continuous polarization with rigid diol BP i. $e$., $\pi-\pi$ bond orientation which makes the entire structure more ordered. In case of homopolyester prepared from sebacoyl chloride with rigid diol BP (5BP), mesomorphic phase was observed in the range of $220-260{ }^{\circ} \mathrm{C}$, because polyester content sebacoyl chloride forms more flexible structure [20-24]. Basic requirement of the formation of mesophase in thermotropic liquid crystalline polymers is presence of rigid rod-flexible spacer system and sebacoyl chloride containing polyester follow the perfectly rigid rod - flexible spacer system.

\section{DSC analysis of AZ series}

The homopolyester, $1 \mathrm{AZ}$, showed only one transition at $145{ }^{\circ} \mathrm{C}$ corresponds to melting transition temperature. No exotherm was observed in the first cooling cycle. It indicates that there is no formation of mesophasic phase, thus, it did not show any characteristics of liquid crystalline phase. The copolyester, 2AZ, manifested two transitions at $161{ }^{\circ} \mathrm{C}$ and $208{ }^{\circ} \mathrm{C}$ which correspond to glass and melting 
transition temperatures. This copolyester exhibited liquid crystalline phase in the range of 210-236 ${ }^{\circ} \mathrm{C}$. Typical polarizing optical micrograph of $2 \mathrm{AZ}$ during heating depicted in Figure 4 and it displayed smectic focal conic texture at $224{ }^{\circ} \mathrm{C}$. Similarly, copolyester $3 \mathrm{AZ}$ showed three transitions at $129^{\circ} \mathrm{C}, 142{ }^{\circ} \mathrm{C}$ and $158^{\circ} \mathrm{C}$. Glass transition temperature appears at $129{ }^{\circ} \mathrm{C}$ whereas two melting transition temperatures show at $142{ }^{\circ} \mathrm{C}$ and $158{ }^{\circ} \mathrm{C}$. This copolyester allowed liquid crystalline phase in the range of $209-250{ }^{\circ} \mathrm{C}$. Similarly, copolyester $4 \mathrm{AZ}$ showed three transitions at $145^{\circ} \mathrm{C}, 177^{\circ} \mathrm{C}$ and $201{ }^{\circ} \mathrm{C}$. Glass transition temperature was appeared at $145{ }^{\circ} \mathrm{C}$ whereas two melting transition temperatures were observed at 142 ${ }^{\circ} \mathrm{C}$ and $158{ }^{\circ} \mathrm{C}$. This copolyester showed liquid crystalline phase in the range of $194-265{ }^{\circ} \mathrm{C}$. Copolyester $5 \mathrm{AZ}$ did not show glass transition temperature whereas it exhibited two melting peaks at $178^{\circ} \mathrm{C}$ and $207{ }^{\circ} \mathrm{C}$. It also showed the mesomorphic in the range of $190-246^{\circ} \mathrm{C}$.

Almost all the polyesters of this series display glass transitions and melting transitions as well as two exotherms during cooling indicates that the samples maintain crystallinity even in cooling cycle. Mesomorphism was observed almost in all polyester samples namely $2 \mathrm{AZ}, 3 \mathrm{AZ}, 4 \mathrm{AZ}$ and $5 \mathrm{AZ}$ (except $1 \mathrm{AZ}$ ) [25-28]. This series reveals that homopolyesters prepared by using fumaroyl chloride is non- liquid crystalline while others are liquid crystalline.

\section{DSC analysis of AX series}

DSC data for the series of polyesters based on 4,4'-dihydroxyazoxybenzene (AX) is presented in Table 3. Homopolyester 1AX displayed melting transition at $143^{\circ} \mathrm{C}$; however, in the corresponding cooling cycle no exotherm was noted. It demonstrates that no mesophasic phase formation takes place, thus, it did not show any characteristics of liquid crystalline phase. Copolyester 2AX allowed two transitions of melting at $140{ }^{\circ} \mathrm{C}$ and $164^{\circ} \mathrm{C}$. On cooling, large exothermic peak extending from $150-50{ }^{\circ} \mathrm{C}$ was recorded. On second heating it showed liquid crystalline phase in the range of $219-250{ }^{\circ} \mathrm{C}$. Copolyester $3 \mathrm{AX}$ exhibited two melting transitions at $142^{\circ} \mathrm{C}$ and $158^{\circ} \mathrm{C}$ while on cooling exotherm was observed in the range of 160-170 ${ }^{\circ} \mathrm{C}$. On second heating it manifested liquid crystalline phase in the range of $209-250^{\circ} \mathrm{C}$. The glass transition at $145{ }^{\circ} \mathrm{C}$ was observed in copolyester 4AX followed by melting transition at $156{ }^{\circ} \mathrm{C}$. On second heating it revealed liquid crystalline phase in the range of $190-265^{\circ} \mathrm{C}$. The copolyester $5 \mathrm{AX}$ showed two transitions at 143 ${ }^{\circ} \mathrm{C}$ and $168{ }^{\circ} \mathrm{C}$. On cooling, two exotherms were observed at $160{ }^{\circ} \mathrm{C}$ and $120{ }^{\circ} \mathrm{C}$. On second heating it allowed liquid crystalline phase in the range of $190-260^{\circ} \mathrm{C}$.

Figure $4 . \quad$ Optical
polarizing micrograph of
$2 \mathrm{AZ}$ at $224 \quad{ }^{\circ} \mathrm{C}$ during
heating
$32 \mathrm{X}$ )

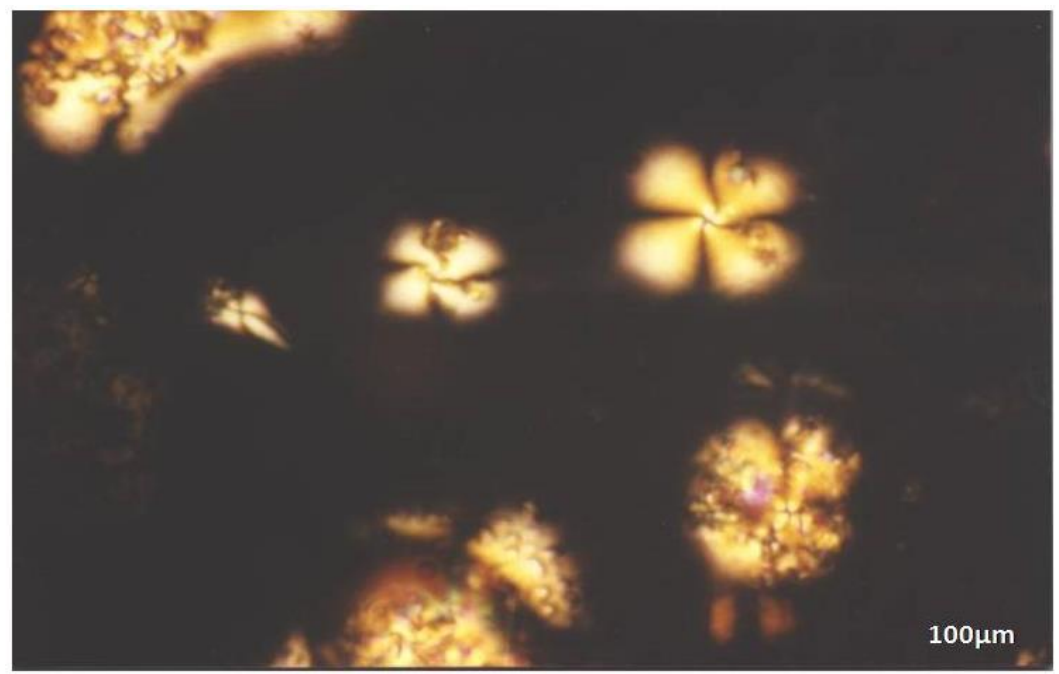


Mesomorphism was observed in homopolyester 5AX and was also marked in copolyesters 2AX, 3AX and 4AX. This series retained liquid crystallinity till incorporation of $75 \%$ of unsaturated fumaroyl chloride spacer with respect to sebacoyl chloride. This AX diol has been extensively studied earlier in the synthesis of thermotropic liquid crystalline polyesters [29-33]. Asrar et al. [34] discussed the structure-property relationship between replacements of central azo or azoxy as bridging group in mesogen along with other substituent at different positions. Azoxy polyesters were found to have higher transition temperature compared with their azo analogue. Polyester synthesized in present study reveals greatest tolerance towards stabilization of liquid crystalline phase even after incorporation of high mole ratio of rigid aliphatic spacer.

\section{DSC analysis of AXM series}

In the all polyesters of AXM series, no particular trend was observed. Mesomorphism was perceived in copolyesters when fumaroyl chloride content below $50 \%$ with respect to sebacoyl chloride. Thermotropic liquid crystallinity is observable over a wide temperature range in polyesters with azoxybenzene moiety in the main chain. AXM series showed lower liquid crystalline phase transition temperatures than AX series due to methyl substitution [16, $35,36]$.

Figure 5. Optical polarizing micrograph of $5 \mathrm{BC}$ at $191{ }^{\circ} \mathrm{C}$ during heating (Magnification 10X)

\section{$D S C$ of $B C$ series}

BC copolyester series shows decreasing order in melting temperatures (Tm) except 4BC. In general, glass transition temperature decreases with increase in content of flexible spacer (sebacoyl chloride). Copolyesters 1BC, 2BC, 3BC and 4BC manifested melting transitions at $200,150,128$ and $181{ }^{\circ} \mathrm{C}$, respectively, whereas homopolyester $5 \mathrm{BC}$ displayed two melting transitions at $107^{\circ} \mathrm{C}$ and $146^{\circ} \mathrm{C}$. In addition to that it showed liquid crystalline phase in the temperature range of 170-196 ${ }^{\circ} \mathrm{C}$. Homopolyester 5BC marked two transitions as mentioned above and were retained in the second heating cycle. On cooling, exotherm was observed at $102^{\circ} \mathrm{C}$.

During heating $\mathrm{BC}$ polyesters appear to be easily cured which prevents flow and formation of liquid crystalline phase. High performance polymers and photo crosslinkable liquid crystalline polymers prepared by using diols applied in electro optical devices were already known [37-39]. Alternatively, the mesogen may be highly extended due to fumaroyl unit, which leads to highly rigid non-melting polyester. Typical polarizing optical micrograph of 5BC (during heating) depicted in Figure 5 and shows marble texture at $191^{\circ} \mathrm{C}$.

\section{DSC of BM series}

BM copolyester series did not show glass transition temperatures except 4BM and also did not demonstrate any definite trend in melting temperature.

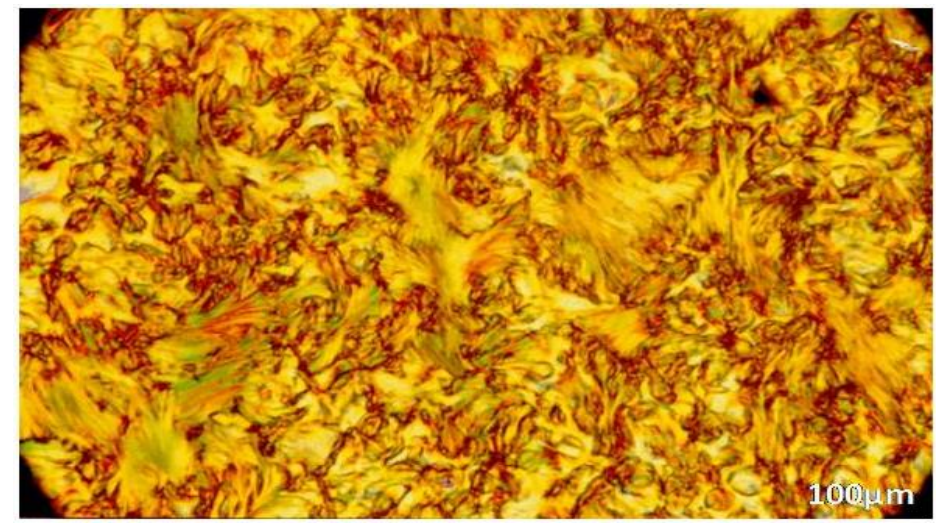


Homopolyester 5BM displayed two melting transitions at $124{ }^{\circ} \mathrm{C}$ and $182{ }^{\circ} \mathrm{C}$. In addition, it revealed short liquid crystalline phase at the temperature ranging from 170 to $185^{\circ} \mathrm{C}$.

Even in the absence of fumaroyl chloride, for 5BM and 5BC, crosslinking took place during heat treatment while observing mesomorphism. To overcome this drawback, we use to keep hot stage at predetermined temperatures and checked the samples. After many trials we were successful in observing the liquid crystalline temperature range for said polyesters. This result itself indicates that apart from fumaroyl chloride's double bond, the double bonds present in diol itself play a role in crosslinking mechanism. Methyl substitution to bis(benzylidene) cyclohexanone diol did not play the significant change in behavior of homo and copolyesters as observed from BM series.

\section{DSC analysis of BHOC series}

BHOC polyester series did not reveal any glass transition temperature but it showed melting transitions. The homopolyester $1 \mathrm{BHOC}$ allowed three melting transitions at $145,163{ }^{\circ} \mathrm{C}$ and $174^{\circ} \mathrm{C}$ whereas copolyester $2 \mathrm{BHOC}$ showed only one melting transition at $335{ }^{\circ} \mathrm{C}$, which could be decomposition. On the contrary, copolyester 3BHOC exhibited two melting transitions at $144{ }^{\circ} \mathrm{C}$ and $250{ }^{\circ} \mathrm{C}$ whereas copolyester 4BHOC showed only one melting transition at $132{ }^{\circ} \mathrm{C}$. Copolyester 5BHOC displayed glass transition temperature at 206
${ }^{\circ} \mathrm{C}$. It allows liquid crystalline phase in the temperature range of 216-285 ${ }^{\circ} \mathrm{C}$. Homopolyester 5BC marked two transitions as mentioned above and were retained in the second heating cycle. On cooling, exotherm was observed at $102{ }^{\circ} \mathrm{C}$. Schlieren nematic texture collected from optical polarizing micrograph of 5BHOC during heating at $227^{\circ} \mathrm{C}$ (Figure 6).

To summaries, total seven rigid diols were used for the synthesis of homo and copolyesters in which fumaroyl chloride was used as rigid aliphatic spacer whereas sebacoyl chloride was utilized as flexible aliphatic spacer. In the present research study, total 35 polyesters were synthesized by interfacial polymerization method and out of that fifteen polyesters show liquid crystalline phase. Copolyester series based on AZ and AX showed almost two melting transitions whereas rest of the polyesters showed mostly only one melting transition. Comparative study of aromatic rigid diols with respect to liquid crystalline nature indicates that azoxy based copolyester systems containing sebacoly chloride (AX, AZ and AXM) manifests liquid crystalline phase.

It is interesting to note that copolyester 5BP shows smectic batonnet texture at $246{ }^{\circ} \mathrm{C}$ whereas copolyester $2 \mathrm{AZ}$ allows smectic focal conic texture at $224{ }^{\circ} \mathrm{C}$. Copolyester (5BC) derived from cyclohexanone exhibits marvelous marble texture at $191{ }^{\circ} \mathrm{C}$ whereas 5BHOC displays normal schlieren nematic texture at $227^{\circ} \mathrm{C}$.

Figure 6. Optical polarizing micrograph of $5 \mathrm{BHOC}$ at $227{ }^{\circ} \mathrm{C}$ during heating (Magnification 10X)

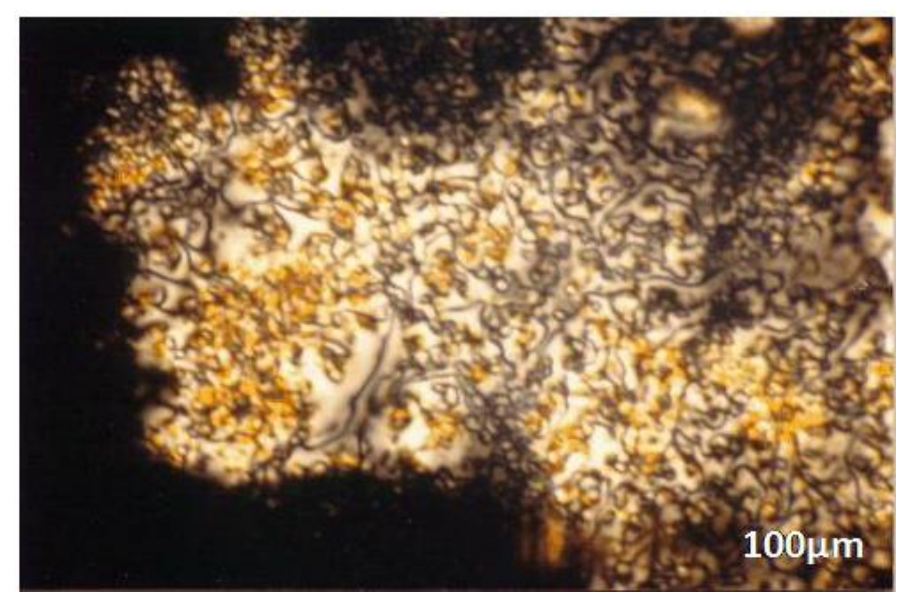




\section{Conclusion}

The incorporation of flexible aliphatic sebacoyl spacer partially into the rigid fumaroyl aliphatic spacer upto $75 \%$ did not form mesophasic character of the polyester based on 4,4'dihydroxy biphenyl. BP diol showed liquid crystallinity when $100 \%$ of flexible sebacoyl chloride is present in the main chain. The effect of rigid and flexible spacer also depends on the type of mesogenic moiety along the main chain. In corporation of fumaroyl chloride into the aromatic rigid main chain did not show liquid crystallinity. It might be due to the extended $\pi$ $\pi$ orientation along the main chain, as it formed more rigid structure. To observe liquid crystalline phase in thermotropic system, rigidflexible system is essential. Thus, almost all the homopolyesters prepared from the sebacoyl chloride with rigid aromatic diols displayed liquid crystalline phase. From the thermotropic liquid crystal point of view, azo and azoxy systems showed better bridging groups for the formation of liquid crystalline phase.

\section{Acknowledgment}

We are thankful to "Department of Science and Technology (DST), Government of India, New Delhi, Grant number SR/S3/CE/0049/2010" for financial support.

\section{Disclosure statement}

No potential conflict of interest was reported by the authors.

\section{References}

[1] a) M. Jaffe, S. Cheng, T. Chung, Y. Freidzon, A. East, Thermotropic Liquid Crystalline Polymers, Encyclopedia of Polym. Sci. and Tech., John Wiley and Sons, 2018, pp 124; b) D. Pavel, D. Hibbs and R. Shanks; Adv. Res. Polym. Sci., 2006, 65-84; c) C.K.S. Pillai, J. Intellect. Property Right., 1999, 4, 274-285; d) T. Ueda, M. Koyama, K. Hayashi, 2009, US Patent 7563554.
[2] a) G. Park, J. Chang, A. Lim, Polymers, 2019, 11, 992-1006; b) H. Nilsson, J. Andersen, 2010, EP Patent 1915387

[3] a) M. Sugantha, D. Roop Singh, Int. J. ChemTech Res., 2017, 10, 216-224; b) D. Jani, J. Kunzler, J. Salmone, 2005, US patent 254003.

[4] J.C. Lee, M.H. Litt, C.E. Rogers, Macromolecules, 1998, 31, 2440-2446.

[5] W. Mormann, M. Brahm, Macromolecules, 1991, 24, 1096-1101.

[6] K. Shiraishi, K. Sugiyama, Chem. Lett., 1990, 19, 1697-1700.

[7] W. Mormann, J. Zimmermann, Macromol. Sympo., 1995, 93, 97-101.

[8] A. Shiota, C. Ober, Prog. Polym. Sci., 1997, 22, 975-1000.

[9] W-F.A. Su, J. Polym. Sci. Polym. Chem. 1993, 31, 3251-3256.

[10] M. Skrifvars, H.W. Schmidt, J. Appl. Polym. Sci., 1995, 55, 1787-1795.

[11] Y. Hu, H. Wang, D. Schiraldi, A. Hiltner, E. Baer, J. Appl. Polym. Sci., 2007, 105, 30-37.

[12] K. Mulani, M. Momin, N. Ganjave, N. Chavan, Bull. Mater. Sci., 2015, 38, 13011308.

[13] T. Otsu, K. Shiraishi, Macromolecules, 1985, 18, 1795-1796.

[14] K.H. Oh, H. Kim, Y. Seo, RSC Adv., 2017, 7, 29772-29778.

[15] N. Plate, V. Shibaev, Macromol. Chem. Suppl., 1984, 6, 3-26.

[16] a) N. Chavan, K. Mulani, Thermotropic Liquid Crystalline Polyesters. LAP LAMBERT Academic Publishing Co., Verlag, Germany, 2012, ISBN: 978-3-65928760-2; b) K. Mulani, M. Momin, N. Ganjave, N. Chavan, Malay. Polym. J., 2014, 9, 54-61.

[17] a) K.A. Suresh, A. Blumstein, F. Rondelez, J. Phys., 1985, 46, 453-460; b) M. Abd-Alla, K. Aly, A. Hammam, High Perform. Polym., 1989, 1, 223-237; c) K.B Mulani, N.V. Ganjave, N.N. Chavan, Ind. J. Chem. B, 2014, 53B, 359-362; d) N. Manurkar, S. 
More, K. Mulani, N. Ganjave, N. Chavan, J. Chem. Sci., 2017, 129, 1461-1468.

[18] A. Blumstein, S. Vilasagar, S. Ponrathnam, S.B. Clough, R.B. Blumstein, G. Maret, J. Polym. Sci. Polym. Phys., 1982, 20, 877892.

[19] S. Shahbazi, Y. Jafari, F. Moztarzadeh, G. Mohamad Sadeghi, J. Appl. Polym. Sci., 2014, 131, 40932-39.

[20] W. Krigbaum, J. Watanabe, T. Ishikawa, Macromolecules, 1983, 16, 1271-1279.

[21] A. Jannesari, R. Ghaffaniam, F.A. Taromi, N. Mohammadi, J. Appl. Polym. Sci., 2005, 98, 1594-1606.

[22] J. Watanabe, W.R. Krigbaum, J. Polym. Sci., Polym. Phys., 1985, 23, 565-574.

[23] J. Watanabe, W. Krigbaum, Macromolecules, 1984, 17, 2288-2295.

[24] J. Asrar, H. Toriumi, J. Watanabe, W.R. Krigbaum, A. Cifferi, J. Preston, J. Polym. Sci., Polym. Phys., 1983, 21, 1119-1142.

[25] Y. Ogawa, K. Takamizawa, Polymer J., 1989, 21, 551-557.

[26] S. Bualek, R. Zental, Makromol. Chem., 1988, 189, 797-804.

[27] H.K. Hall Jr., T. Kuo, R.W. Lenz, T.M. Leslie, Macromolecules, 1987, 20, 2041-2044.

[28] A. Blumstein, Polym. J., 1985, 17, 277288.
[29] P.A. Drewes, A.J. Kowalski, Clin. Chem., 1974, 20, 1451-1453.

[30] A. Blumstein, G. Maret, S. Vilasagar, Macromolecules, 1981, 14, 1543-1545.

[31] G. Maret, A. Blumstein, Mol. Cryst. Liq. Cryst., 1982, 88, 295-309.

[32] A. Blumstein, S. Vilasagar, S. Ponrathnam, S.B. Clough, R.B. Blumstein, G. Maret, J. Polym. Sci. Polym. Phys., 1982, 20, 877892.

[33] Y. Ozcayir, J. Asrar, S. Clough, A. Blumstein, Mol. Cryst. Liq. Cryst., 1986, 138, 167-178.

[34] J. Asrar, 0. Thomas, Q. Zhou, A. Blumstein, Thermotropic liquid crystalline polyesters: Structure property relationship, Proc. 28th Macromol. Symp. IUPAC, U. Mass., Amherst, MA, Macromol. Symp. 1982, pp 797-803.

[35] A.C. Griffin, S.J. Havens, J. Polym. Sci., Polym. Phys., 1981, 19, 951-969.

[36] Y. Ozcayir, X. Lai, J. Ratio, A. Blumstein, Mol. Cryst. Liq. Cryst., 1990, 185, 75-87.

[37] Gangadhara, K. Kishore, Macromolcules, 1993, 26, 2995-3003.

[38] Gangadhara, K. Kishore, Polymer, 1995, 36, 1903-1910.

[39] M.M. Abd-Alla, M.F. El-Zohry, K.I. Aly, M.M.M. Abd-El-Wahab, J. Appl. Polym. Sci., 1993, 47, 323-329.

How to cite this manuscript: Apparav Wale, Smita Mule, Atul Dhage, Khudbudin Mulani, Surendra Ponrathnam, Nayaku Chavan, Thermotropic Liquid Crystalline Polyesters using Aromatic Rigid Diols, Unsaturated Fumaric Acid and Flexible Sebacic Acid, Adv. J. Chem. A, 2020, 3(4), 510-523.

Copyright (C) 2020 by SPC (Sami Publishing Company)+ is an open access article distributed under the Creative Commons Attribution License, which permits unrestricted use, distribution, and reproduction in any medium, provided the original work is properly cited. 